Journal of Modern Mathematics and Statistics 5 (1): 3-8, 2011

ISSN: 1994-5388

(C) Medwell Journals, 2011

\title{
Stochastic (Multiplicative) Effect of Government Policy on the Income of Individuals
}

\author{
${ }^{1}$ Bright O. Osu, ${ }^{2}$ Godswill U. Achi and ${ }^{1}$ Chigoziem A. Emereuwa \\ ${ }^{1}$ Department of Mathematics, Abia State University, P.M.B. 2000, Uturu, Nigeria \\ ${ }^{2}$ Department of Mathematics, Abia State Polytechnics, Aba, Nigeria
}

\begin{abstract}
This study examines a stochastic effect of the government policy on the income of individuals to explain the aggregate income of individuals whose salaries are increased and invested when received. A single (distribution) probability mass function which accommodates both the risk-free and risky income is presented herein. The result confirms that the aggregate income (wealth) of an individual is distributed according to power law. This distribution is used to solve the Black-scholes PDE. It is discovered that $\alpha$ (the measure exponent of the power law) lies between $(1.2,2.46)$ with the empirical data. We further used this distribution as a special (case) utility function to represent explicitly the optimal policies when there are minimum capital requirement.
\end{abstract}

Key words: Aggregate income, stochastic effect, salaries, capital, power law, probability

\section{INTRODUCTION}

It is well known that the tail of the income distribution obeys a power law:

Where:

$$
\mathrm{P}(\mathrm{I})=\mathrm{CI}^{-(1+\alpha)}
$$

$\mathrm{I}=$ The come

$\alpha=$ Pareto exponent

$\mathrm{C}=$ Normalization constant

Research reveals that the tail exponent fluctuates in a certain interval over years. For example, Souma (2002) and Feenberg and Poterba (1992) reported that the Pareto exponents $\alpha$ of Japan and the US income distribution hover around an interval $(1.5,2.5)$ using tax returns data.

Levy and Solomon (1997), presented a nonconventional approach for studying the distribution of wealth in society. Their finding confirms that power law distribution of wealth (with exponent $\alpha=1.36$ ) has important implications as to the degree of inequality in the society (Slottje, 1989) and as the distribution of stock market fluctuations. Many researchers have attempted to explain the power-law in income distribution by utilizing a multiplicative stochastic process (Manrubia and Zanette, 1999).

In this study, we consider a stochastic effect of government policy on the income of an individual. We view income process as follows: They are two assets which an individual can invest in the economy that yields income. One is the riskless income $\mathrm{I}_{0}(\mathrm{t})$ which has constant interest rate (e.g., job) and the other is the risky income $\mathrm{I}_{1}(\mathrm{t})$ which follows the geometric brownian motion with constant coefficients. The differential forms are given by $\mathrm{dI}_{0}(\mathrm{t})=\Upsilon \mathrm{I}_{0} \mathrm{dt}, \mathrm{dI}_{1}(\mathrm{t})=\mu \mathrm{I}_{1}(\mathrm{t}) \mathrm{dt}+\sigma \mathrm{I}_{1}(\mathrm{t}) \mathrm{dB}(\mathrm{t})$ where $\mathrm{B}(\mathrm{t})$ is a standard brownian motion on a probability space $(\Omega, F, P)$ (Lim and Choi, 2009). The $F$ is a $\sigma$-algbra generated by $B(t), t \geq 0$ (Karatzas and Shreve, 1998) for infinite horizon case.

We present in this study, the distribution of the aggregate income of an individual base on the government policy (upward adjustment of risk-free (salary) and risky income (investment). This distribution is shown to follow the power-law distribution. We further use this distribution as a special case utility function to solve the Black-scholes PDE generated by associating the Ito's formula to the linear form of the risky income.

\section{INCOME AND INCOME DISTRIBUTION}

Consider a system of large set of elements $i$ which are characterized each by a time-dependent variable, $\mathrm{I}_{i}(\mathrm{t})$ (for definiteness one can think of a set of investment $i=1, \ldots$ $N$ each owning an income $I_{i}$. Assume that the typical variations of I are characterized by a stochastic multiplicative law:

$$
I_{i}(t+1)=y_{i}(t+1) I_{i}(t)
$$

Where, $y_{i}$ is a stochastic variable with a finite support distribution of probability $\mathrm{f}(\mathrm{y})$ and I's are normalized I's such as to fulfill at each:

$$
\sum_{i} 1_{i}(t)=\int I P(I, t) d I=N
$$


that is we have represented actually the relative wealth of each investor. In this case, this consists in subsidizing individuals as not to fall below a certain poverty line $\mathrm{I}_{0}(\mathrm{t})$ so, we limit from below the allowed values of $I_{i}(t)>I_{0}(t)$ (Manrubia and Zanette, 1999).

Suppose in Nigeria nation $\mathrm{d}+1$ income are received by individual continuously on a fixed time-horizon $[0, \mathrm{~T}]$, $0<\mathrm{T}<\infty$ (through salary).

The portfolio of the investor is made up of risk free and risky income. The risk free income evolves according to the differential equation:

$$
\mathrm{dI}_{0}(\mathrm{t})=\mathrm{r}(\mathrm{t}) \mathrm{I}_{0}(\mathrm{t}), \mathrm{I}_{0}(0)=\mathrm{i}_{0}, 0 \leq \mathrm{t} \leq \mathrm{T}
$$

The remaining d risky income is modeled by the linear stochastic differential equation:

$$
\begin{aligned}
d_{i}(t)= & I_{i}(t)\left[a_{i}(t) d t+\sum_{j=1}^{d} b_{i, j}(t)\right. \\
& \left.d Z_{i}(t)\right], I_{i}(0)=i_{1}, 0 \leq t \leq T
\end{aligned}
$$

for $i=1,2, . ., d$. Here, $Z=\left\{Z(t)=Z_{i}(t), \ldots, Z_{d}(t), F_{t} 0 \leq t \leq T\right.$ is a d-dimensional wiener process on $(\Omega, F, P)$ and the augmentation under $\mathrm{P}$ of $\mathrm{F}_{\mathrm{t}}=\sigma\left(\mathrm{Z}_{\mathrm{S}}=0 \leq \mathrm{s} \leq \mathrm{t}\right), 0 \leq \mathrm{t} \leq \mathrm{T}$. The interest rate $\left\{r(t), F_{t} ; 0 \leq t \leq T\right\}$ as well as the vector of the mean rates $\left\{\mathrm{b}(\mathrm{t})=\left(\mathrm{b}_{\mathrm{i}, \mathrm{j}}(\mathrm{t})\right)_{1 \leq \mathrm{i}, \mathrm{j} \leq \mathrm{d},} \mathrm{F}_{\mathrm{t}}: 0 \leq \mathrm{t} \leq \mathrm{T}\right\}$ are assumed to be measured, adapted and bounded, uniformly in $(t, \omega) \epsilon$ $[0, \mathrm{~T}] \times \Omega$ (Karatzas et al., 1987). The stochastic process for the value of each risky income (in local-currency terms; Naira) is:

$$
d I_{i}(t)=\alpha I_{i}(t) d t+\sigma I_{i}(t) d Z_{i}(t), i=1, \ldots N
$$

and the aggregate income (wealth) of the investor, $\mathrm{X}_{\mathrm{t}}$ say follows a diffusion given by (with time suppressed):

Where:

$$
\mathrm{dX}=\mathrm{HdI}+\mathrm{r}(\mathrm{X}-\mathrm{HI}) \mathrm{dt}
$$

$$
\mathrm{H}=\left\{\mathrm{H}_{\mathrm{t}}\right\}_{\mathrm{t} 20}
$$

represents the proportion of wealth invested in the risky income with time, t. Equation 5 is the investment policy defined by an F-adapted process. Putting Eq. 5 into 6 gives:

$$
\mathrm{dX}=[\mathrm{rX}+\mathrm{HI}(\alpha-\mathrm{r})] \mathrm{dt}+\mathrm{H} I \sigma \mathrm{dZ}
$$

where, $\alpha-r$ is the risk premium. If $H$ is a replicating portfolio that would track the value of the wealth of the investor (Osu, 2008):

$$
\mathrm{G}(\mathrm{t})=\mathrm{V}(\mathrm{I}, \mathrm{t})
$$

Ito's formula on Eq. 9 gives:

$$
\frac{\partial \mathrm{V}}{\partial \mathrm{t}}+\frac{1}{2} \sigma^{2} \mathrm{I}^{2} \frac{\partial^{2} \mathrm{~V}}{\partial \mathrm{I}^{2}}+\mathrm{rI} \frac{\partial \mathrm{V}}{\partial \mathrm{I}}-\mathrm{rV}=0
$$

Equation 10 is the Black-scholes PDE with terminal condition $V(I, T)=g(I)$. It is a well known fact the Blackscholes PDE can be used for all European contracts depending on the pay off function $g(\mathrm{I})$. For example:

$$
\begin{aligned}
& \text { European calls } g(\mathrm{I})=(1-\mathrm{K})^{+} \\
& \text {European put } \mathrm{g}(\mathrm{I})=(\mathrm{K}-\mathrm{I})^{+} \\
& \text {Digitals calls } \mathrm{g}(\mathrm{I})=\mathrm{V}(1 \geq \mathrm{K})
\end{aligned}
$$

The function $C=V(I, 0)$ when $I=I_{0}$ of the European call is given by the equation:

Where;

$$
C(I, K, \tau, r, \sigma)=I \varnothing\left(d_{1}\right)-K^{-r t} \varnothing\left(d_{2}\right)
$$

$$
\begin{gathered}
\mathrm{d}_{1}=\frac{\operatorname{In}(\mathrm{I} / \mathrm{K})+\left(\mathrm{r}+\sigma^{2} / \alpha\right)}{\sigma \sqrt{\tau}} \\
\mathrm{d}_{2}=\mathrm{d}_{1}-\sigma \sqrt{\tau}
\end{gathered}
$$

and $\varnothing($.$) is the cumulative normal distribution function:$

$$
\varnothing(\mathrm{y})=\frac{1}{2 \pi} \int_{-\infty}^{\infty} \mathrm{e}^{-\mathrm{y}^{2}} / 2 \mathrm{dy}
$$

The parameters that enter Eq. 11 are:

$\mathrm{K}=$ The exercise price or strike price

$\tau=\mathrm{T}-\mathrm{t}=$ The exercise date

$\mathrm{I}=$ The price of the underlying asset

$\mathrm{r}=$ The interest rate

$\sigma \quad=$ The volatility

Of these 5 parameters, the first 4 are observable at any given time ( $\mathrm{r}$ is known for short expiration date) (Osu, 2008). The volatility of the underlying asset is not directly observable. For each value of the volatility parameter, we obtain a different theoretical investment value. Conversely, it is easy to show that each possible investment value (in the range of the formula) there corresponds a volatility parameter.

This is a consequence of the fact that the Blackscholes option premium is a strictly increasing function of $\sigma$. The implied volatility of a traded call is defined by the value of $\sigma$ that solves the equation $C(I, K, K, r, \sigma)=$ market price of the call. At anytime $t \in[0, T]$, the value function $V(I, t)$ of a call option involves $\alpha_{t}$ share of investment and $\beta_{\mathrm{t}}$ units of monthly pay off funds in form of salary where: 


$$
\left.\begin{array}{l}
\propto_{t}=\mathrm{C}_{\mathrm{I}}(\mathrm{I}, \tau)=\varnothing\left(\mathrm{d}_{1}(\mathrm{I}, \tau)\right) \\
\beta_{\mathrm{t}}=\mathrm{C}(\mathrm{I}, \tau)-\propto_{\mathrm{t}} \mathrm{I}
\end{array}\right\}
$$

Proposition 1: If the value function is (i) replicating then:

$$
\mathrm{V}_{\mathrm{t}}=\mathrm{C}(\mathrm{I}, \tau) \forall \mathrm{t} \in[0, \mathrm{~T}]
$$

and (ii) self-financing then:

$$
2 \mathrm{C}_{\tau}=\mathrm{I} \sigma \varnothing\left(\mathrm{d}_{1}\right)+2 \mathrm{Kr} \sqrt{\tau} \varnothing\left(\mathrm{d}_{2}\right) \mathrm{e}^{-\mathrm{r \tau}}=0
$$

Proof : We write the value function as Eq. 11 so that:

$$
\begin{gathered}
\mathrm{C}_{\mathrm{I}}=\varnothing\left(\mathrm{d}_{1}\right), \mathrm{C}_{11}=\frac{\varnothing\left(\mathrm{d}_{1}\right)}{\mathrm{I} \sigma \sqrt{\tau}} \\
\mathrm{C}_{\tau}=\frac{1 \sigma}{2 \sqrt{\tau}} \varnothing\left(\mathrm{d}_{1}\right)+\mathrm{Kre}^{-\mathrm{rt}} \varnothing\left(\mathrm{d}_{2}\right), \mathrm{C}_{\sigma}=\mathrm{I} \sqrt{\tau} \varnothing\left(\mathrm{d}_{1}\right) \\
\mathrm{C}_{\mathrm{r}}=\tau \mathrm{ke}^{-\mathrm{rt}} \varnothing\left(\mathrm{d}_{2}\right), \mathrm{C}_{\mathrm{K}}=-\mathrm{e}^{-\mathrm{rt}} \varnothing\left(\mathrm{d}_{2}\right)
\end{gathered}
$$

Consider a portfolio made of $\alpha_{t}$ stocks and $\beta_{t}$ risk less asset:

$$
\begin{aligned}
\mathrm{V}_{\mathrm{t}} & =\alpha_{\mathrm{t}} \mathrm{I}+\beta_{\mathrm{t}} \\
& =\mathrm{I} \varnothing\left(\mathrm{d}_{1}\right)+\mathrm{C}(\mathrm{I}, \mathrm{t})-\mathrm{I} \varnothing\left(\mathrm{d}_{1}\right) \\
& =\mathrm{C}(\mathrm{I}, \mathrm{t})
\end{aligned}
$$

Hence, $\mathrm{V}$ is replicating. We now verify that $\mathrm{V}$ is self-financing. Write :

$$
\begin{aligned}
& \mathrm{dV}_{\mathrm{t}}=\mathrm{d}\left(\frac{\partial \mathrm{C}}{\partial \mathrm{I}}\right) \mathrm{I}+\mathrm{d}\left(\mathrm{C}-\frac{\partial \mathrm{C}}{\partial \mathrm{I}} \mathrm{I}\right) \\
& =\mathrm{d}(\mathrm{C}(\mathrm{I}, \mathrm{t}))-\frac{\partial \mathrm{C}}{\partial \mathrm{I}} \mathrm{dI}+\left(-\mathrm{rC}+\mathrm{r} \frac{\partial \mathrm{C}}{\partial \mathrm{I}} \mathrm{I}\right) \mathrm{dt} \\
& =\frac{\partial \mathrm{C}}{\partial \mathrm{t}}+\frac{1}{2} \sigma^{2} \mathrm{I}^{2} \frac{\partial^{2} \mathrm{C}}{\partial \mathrm{I}^{2}}+\mathrm{rI} \frac{\partial \mathrm{C}}{\partial \mathrm{I}}-\mathrm{rC}=0 \\
& \frac{\mathrm{I} \sigma \varnothing\left(\mathrm{d}_{1}\right)}{2 \sqrt{\tau}}+\mathrm{Kre}^{-\mathrm{r} \tau} \varnothing\left(\mathrm{d}_{2}\right)+\frac{\sigma^{2} \mathrm{I}^{2}}{2 \sigma \mathrm{I} \sqrt{\tau}} \varnothing\left(\mathrm{d}_{1}\right)+\mathrm{rI} \varnothing\left(\mathrm{d}_{1}\right)- \\
& \Rightarrow{ }_{\mathrm{rI}} \varnothing\left(\mathrm{d}_{2}\right)+\mathrm{Kre}^{-\mathrm{r \tau}} \varnothing\left(\mathrm{d}_{2}\right)=0 \\
& \Rightarrow \operatorname{I\sigma } \varnothing\left(\mathrm{d}_{2}\right)+2 \mathrm{Kre}^{-\Upsilon \tau} \sqrt{\tau} \varnothing\left(\mathrm{d}_{2}\right)=0 \\
& =2 \mathrm{C}_{\tau} \text { (as required) }
\end{aligned}
$$

Derivation of aggregate mass function as a special utility function: Investors in markets (including markets for insurance and energy risk) often find that these markets are incomplete. In order to price contingent claims in these markets, it is necessary to use assumptions about the agents in the economy and their preferences in order to determine an equivalent martingale measures to use for pricing. One approach is based on an expected utility. Consider an economy at time $\mathrm{t}$ consisting of individuals with function over income given by Cochrane (2001):

$$
U\left(I_{t}, I_{t+1}\right)=U\left(I_{t}\right)+E_{t}\left[U\left(I_{t+1}\right)\right]
$$

Where, $\mathrm{E}_{\mathrm{t}}$ is the conditional expectation operator over future states at time $t+1$. If we consider the marginal propensity to consume and marginal propensity to invest, we may write:

$$
\mathrm{E}_{t}\left[\mathrm{U}\left(\mathrm{I}_{\mathrm{t}+1}\right)\right]=\vartheta+\beta \mathrm{U}\left(\mathrm{I}_{\mathrm{t}}, \mathrm{I}_{\mathrm{t}+1}\right)
$$

Where, $\vartheta$ and $\beta$ are the marginal propensity to consume and marginal propensity to invest then Eq. 15 becomes:

$$
\mathrm{U}\left(\mathrm{I}_{\mathrm{t}}, \mathrm{I}_{\mathrm{t}+1}\right)=\mathrm{U}\left(\mathrm{I}_{\mathrm{t}}\right)+\vartheta+\beta \mathrm{U}\left(\mathrm{I}_{\mathrm{t}}, \mathrm{I}_{\mathrm{t}+1}\right)
$$

or;

$$
\mathrm{U}\left(\mathrm{I}_{\mathrm{t}, \mathrm{t}+1}\right)=\frac{\vartheta+\mathrm{U}\left(\mathrm{I}_{\mathrm{t}}\right)}{1-\beta}
$$

Theorem: Given Eq. 17, the special utility function is given as:

$$
V(I)=\frac{I^{-(1+\alpha)}}{1-\beta}
$$

Proof : Let $U\left(I_{t}\right)=\lambda(t) I_{i}(t)$ where, $\lambda(t)$ is the total stochastic growth rate of investment by an investor. If these growth rates are independently and identically distributed random variables with density function $f(\lambda)$ and that the average normalized size must stay constant that is:

$$
\int_{0}^{\infty} \lambda \mathrm{f}(\lambda) \mathrm{d} \lambda=1
$$

we can express Eq. 17 in terms of cumulative distribution of $\mathrm{I}_{\mathrm{i}}(\mathrm{t})$ (Ioannides and Overman, 2000), $\mathrm{V}(\mathrm{I}, \mathrm{t})$ gives:

$$
V(I, 1+t)=\frac{1}{1-\beta} \int_{\lambda} G\left(\frac{1}{\lambda}, t\right) F(\lambda) d \lambda
$$

where all values of $\lambda$ such that the investments at $\mathrm{t}+1$ are equal $1 / \lambda . \lambda=1$ is are accounted for and $\mu(\vartheta)=\int \vartheta d t=0$ (Hewitt and Stromberg, 1960). Equation 19 now becomes (Levy, 2001):

$$
V(I)=\frac{1}{1-\beta} \int G\left(\frac{1}{\lambda}\right) F(\lambda) d \lambda
$$

this equals: 


$$
\begin{aligned}
v(x) & =\frac{1}{1-\beta} \int f(\lambda) g(x-\lambda) d \lambda \\
& =\frac{e^{-n x}}{1-\beta}
\end{aligned}
$$

Translating back to original variable $\mathrm{I}=\mathrm{e}^{\mathrm{x}}$, we have (Osu and Alfred, 2008):

$$
\mathrm{V}(\mathrm{I})=\frac{1^{-(1+\alpha)}}{1-\beta}
$$

Solution of Black-sholes PDE by the special utility function: Without loss of generality, we assume the wealth of an investor in a finite horizon follows the process:

$$
\mathrm{dI}=\hat{\alpha} \mathrm{I}_{\mathrm{i}}(\mathrm{t}) \mathrm{dt}+\sigma \mathrm{I}_{\mathrm{i}} \mathrm{dZ}_{\mathrm{i}}(\mathrm{t}), \hat{\alpha}=\alpha+\gamma
$$

The resulting PDE using the standard approach to stochastic dynamic programming with Ito formula is the backward Black-scholes PDE given by:

$$
\frac{\partial \mathrm{V}}{\partial \mathrm{t}}+\frac{1}{2} \sigma^{2} \mathrm{I}^{2} \frac{\partial^{2} \mathrm{~V}}{\partial \mathrm{I}^{2}}+(\alpha-\gamma) \mathrm{I} \frac{\partial \mathrm{V}}{\partial \mathrm{I}}-\mathrm{rV}=0
$$

Where, $\gamma=0$ is the market price of risk so that:

$$
\frac{\partial \mathrm{V}}{\partial \mathrm{t}}+\frac{1}{2} \sigma^{2} \mathrm{I}^{2} \frac{\partial^{2} \mathrm{~V}}{\partial \mathrm{I}^{2}}+\alpha \mathrm{I} \frac{\partial \mathrm{V}}{\partial \mathrm{I}}-\mathrm{rV}=0
$$

Denoting the proportion of wealth invested in asset $\mathrm{i}$ by $\left.\mathrm{I}_{\mathrm{i}}=1,2, \ldots, \mathrm{n}\right)$, the investor's problem at time $\mathrm{t}$ can be written as:

$$
V(I)=\max E\left[\frac{I_{T}^{-(1+\alpha)}}{1-\beta}\right]
$$

subject to the dynamics of wealth as in Eq. 22 .

Where:

$\sigma=$ Vector volatilities

$\mathrm{dZ}=$ Vector of diffusion shocks with dot product $\sigma \cdot \mathrm{dZ}(\mathrm{t})$

We have considered an investor who wishes to maximize the expected utility from terminal wealth (here intermediate consumption is not considered because it has no effect in the model), $\mathrm{I}_{\mathrm{T}}$ with utility being given by:

$$
V\left(I_{T}\right)=\frac{I^{-(1+\alpha)}}{1-\beta}
$$

where, $0<\beta<1$ so that the constant relative risk aversion is equal to $\beta$ (if $\beta=1$, the utility function is $V\left(I_{T}=\operatorname{InI}_{T}\right.$ ). By Das and Uppal (2004), the investor can allocate funds across $\mathrm{i}=\{0,1, \ldots, \mathrm{n}\}$ assets: a riskless assets denominated in U.S dollars $(i=0)$, a risky U.S. equity index $(i=0)$ and risky foreign equity indexes, $i=\{2, \ldots, n\}$.

Proposition 1: If the function $V\left(I_{i}, t\right)$ defined in Eq. 25 is the solution to the PDE defined in Eq. 24. Then $\alpha>0$ is a solution the characteristic equation:

$$
\alpha^{2}-\alpha-\frac{2 \mathrm{r}}{\sigma^{2}+2}=0
$$

The positive root is:

$$
\alpha=\frac{1}{2}\left\{1+\sqrt{1+\frac{8 \mathrm{r}}{\sigma^{2}+2}}\right\}
$$

This is the pareto exponent of the special utility function. The exponent carries over to the distribution of income I (Nirei and Souma, 2003). From Eq. 27, we determine $\alpha$ when oand $\Upsilon$ are known. $\Upsilon$ is the cumulative of the interest rate from investments and the rate of government policy in upward salary adjustment. We obtain different values of $\alpha$ by the data analysis made from the collection of aggregate income (from salary and investment) of individuals.

The values are estimated from the income growth rates of 400 low income, 400 middle income and 400 high income individuals in civil service (Umuahia Abia state Nigeria) during 2005-2009.

The growth rate for the low income individuals has mean 1.53 and standard deviation 0.22 . Then the normalized income has an annual standard deviation $0.22 / 1.53$. That is as for $\sigma$, we use a constant $0.22 / 1.53$. The income growth rate $r=0.2425$. Applying $r=0.2425$ and $\sigma=0.146$ to Eq. 27 , we obtain $\alpha=1.2$. For the middle income individuals, the growth rate has mean 4.8234 and standard deviation $0.1696, \mathrm{r}=2.09$ normalized annual standard deviation $0.1696 / 4.8234=0.0352$ and $\alpha=2.02$ by Eq. 27. The high income individuals have mean 4.8, standard deviation $0.17, \mathrm{r}=3.66$, normalized annual standard deviation $0.17 / 4.8=0.04$ and $\alpha=2.46$ using Eq. 27. Figure la-c shows the income of individuals with different values of the parameters $(r, \sigma, \alpha)$ due to different investment policies. By the method of change of independent variable, Eq. 24 becomes:

$$
\frac{1}{2} \sigma^{2} D^{2} V+\left(\alpha-\frac{\sigma^{2}}{2}\right) D V-\Upsilon V=e^{x}
$$



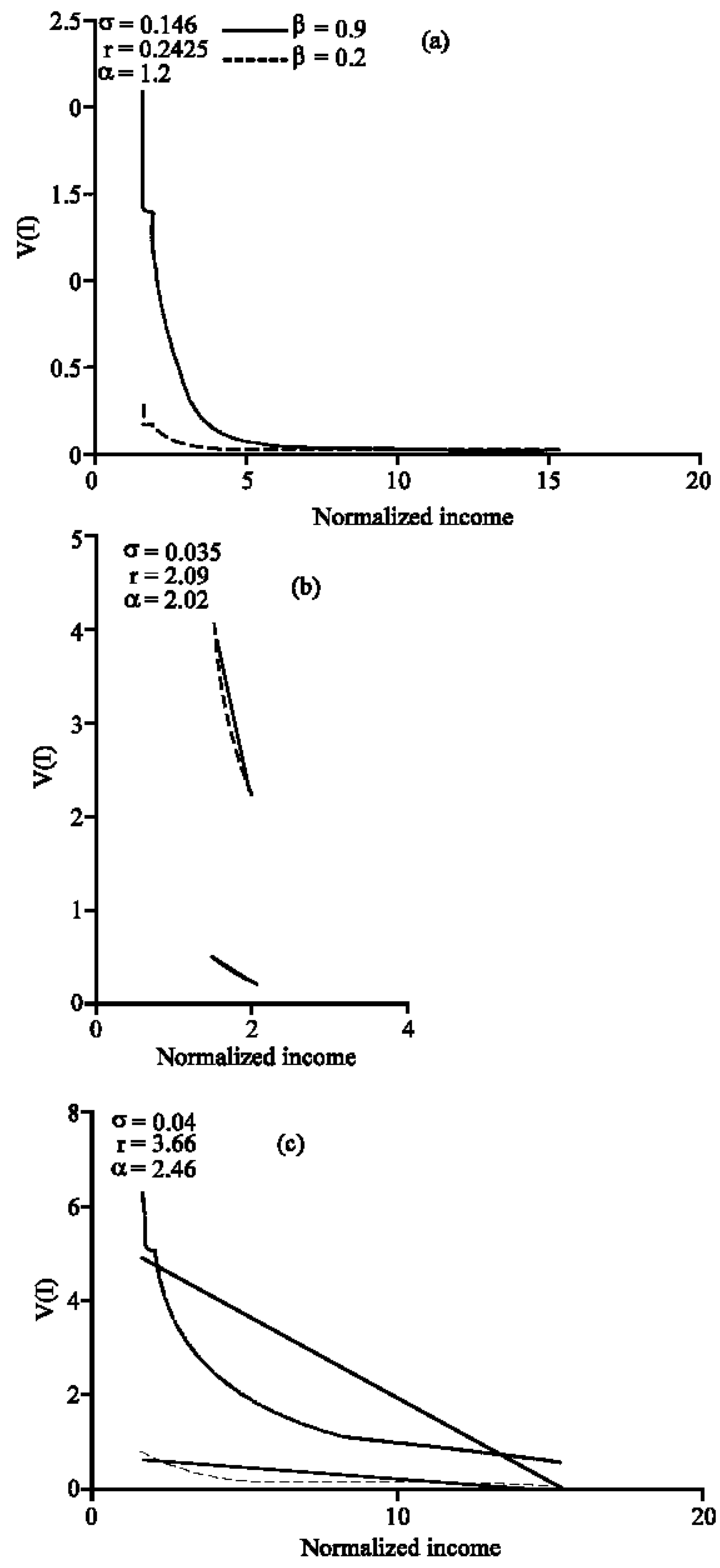

Fig. 1: (a-c) A power law distribution of aggregate income between different individual and their propensity to invest. It implies a relation between the rank of an individual in the wealth hierarchy and his wealth. Figure 1 shows sets of individuals with the same salary but different investment policies $\beta$. The straight lines are the power law fits on a log$\log$ scale

The homogenous part of Eq. 28 gives (Osu et al., 2009):

$$
\mathrm{D}^{2} \mathrm{~V}+\left(\frac{2 \alpha}{\sigma^{2}}-1\right) \mathrm{DV}-\frac{2 \mathrm{r}}{\sigma^{2}} \mathrm{~V}=0
$$

with a positive root:

$$
\gamma=\frac{1}{2}\left\{\left(1-\frac{2 \alpha}{\sigma^{2}}\right)+\sqrt{\left(\frac{2 \alpha}{\sigma^{2}}-1\right)^{2}+\frac{8 r}{\sigma^{2}}}\right\}
$$

Equation 30 equivalent to that in Nirei and Souma (2003) is the Pareto exponent if the lower bound does not grow.

\section{CONCLUSION}

We have considered a stochastic effect of the government policy on the income of individuals. We obtained inEq. 18 a formula (Nirei and Souma, 2003) which we claimed is related to the pareto law in the investors' wealth.

Equation 18 is the optimal policy of an investor when there are minimum capital requirements. The investors' wealth increases (decreases) according as $\beta(0 \leq \beta<1)$ increases (decreases).

$\beta$ actually is the marginal propensity for the investor to save that is invest for future hence to avert risk of falling back below income level if the government policy becomes a downward decrement of salaries of her workers (as normally is the case in some develop countries in resent times). We obtained explicitly in Eq. 27 a formula for the power law exponent of income distribution. This exponent is volatile and large (1.2-2.46) because the income of individuals has a lower bound growing as fast as the entire distribution due to salary upward adjustment by the government policy.

\section{REFERENCES}

Cochrane, J.H., 2001. Asset Pricing. Princeton University Press, Princeton.

Das, S.R. and R. Uppal, 2004. Systemic risk and international portfolio choice. J. Finan., 59: 2809-2834.

Feenberg, D.R. and J.M. Poterba, 1992. Income inequality and the incomes of very high income tax payers: Evidence from tax returns. Tax Policy Econ., 7: 145-177.

Hewitt, E. and K. Stromberg, 1960. Real and Abstract Analysis. 2nd Edn., Springer-Verlag, New York, pp: 355 .

Ioannides, Y.M. and H.G. Overman, 2000. Zipfs law for cities: An empirical examination. Centre for Economic Performance, London. http://ideas.repec.org/p/cep/ cepdps/dp0484.html. 
Karatzas, I. and S.E. Shreve, 1998. Methods of Mathematical Finance. 1st Edn., Springer-Verlag, New York, ISBN: 978-0-387-94839-3, pp: 415.

Karatzas, I., J.P. Lehoczky and S.E. Shreve, 1987. Optimal portfolio and consumption decisions for a small investor on a finite horizon. SIAM J. Control Optim., 25: 1557-1586.

Levy, M. and S. Solomon, 1997. New evidence for the power-law distribution of wealth. Phys. A: Stat. Theor. Phys., 242: 90-94.

Levy, M., 2001. Market efficiency, the pareto wealth distribution and the levy distribution of stock returns. The Jerusalem School of Business Administration, Hebrew University of Jerusalem, Israel.

Lim, B.H. and U.J. Choi, 2009. Optimal consumption and portfolio selection with portfolio constraints. Int. J. Contemp. Math. Sci., 4: 293-309.

Manrubia, S.C. and D.H. Zanette, 1999. Stochastic multiplicative processes with result events. Phys. Rev. E, 59: 4945-4948.
Nirei, M. and W. Souma, 2003. Income Distribution and Stochastic Multiplicative Process with Reset Events. In: The Complex Dynam-ics of Economic Interaction, Gallegati, M., A. Kinman and M. Narsili (Eds.). Springer, New York.

Osu, B.O. and C.O. Alfred, 2008. A stochastic analysis of the effect of sudden increase in the income of individuals on the economy. Asian J. Math. Statist., 1: $69-79$.

Osu, B.O., 2008. A stochastic analysis of the effect of sudden increase in the income of individuals on the Nigeria economy. Ph.D. Thesis, Department of Mathematics Abia State University Uturu, Nigeria.

Osu, B.O., A.C. Okoroafor and C. Olunkwa, 2009. Stability analysis of stochastic model of stock market price. Afr. J. Math. Comp. Sci. Res., 2: 098-103.

Slottje, D.J., 1989. The Structure of Earnings and the Measurement of Income Inequality in the US. Elsevier Science Publishers, New York.

Souma, W., 2002. Physic of Personal Income. In: Empirical Science of Financial Fluctuations: The Advent of Econophysics, Takayasu, H. (Ed.). Springer, Tokyo, pp: 343-352. 